\title{
Stress and Disease: Is Being Female a Predisposing Factor?
}

\author{
Jill B. Becker, ${ }^{1}$ Lisa M. Monteggia, ${ }^{2}$ Tara S. Perrot-Sinal, ${ }^{3}$ Russell D. Romeo, ${ }^{4}$ Jane R. Taylor,,${ }^{5}$ Rachel Yehuda, ${ }^{6}$ and \\ Tracy L. Bale ${ }^{7}$ \\ ${ }^{1}$ Department of Psychology, University of Michigan, Ann Arbor, Michigan 48109, 2Department of Psychiatry, The University of Texas Southwestern \\ Medical Center, Dallas, Texas 75390, ${ }^{3}$ Department of Psychology, Dalhousie University, Halifax, Nova Scotia, Canada B3H 4R2, ${ }^{4}$ Department of Psychology, \\ Barnard College, New York, New York 10027, ${ }^{5}$ Department of Psychiatry, Yale University School of Medicine, New Haven, Connecticut 06510, ${ }^{6}$ Department \\ of Psychiatry, James J. Peters VA Medical Center, Bronx, New York 10468, and 7Department of Animal Biology, University of Pennsylvania, Philadelphia, \\ Pennsylvania 19104
}

Key words: addiction; depression; HPA axis; animal models; sex; stress

Does heightened stress sensitivity predispose an individual toward disease? Our Society for Neuroscience mini-symposium examines the link between stress and disease onset, exploring sex differences and whether there is an increased female predisposition. This session specifically addresses the influence of stress sensitivity in the fields of drug addiction and affective disorders. As the incidence of stress-related diseases continues to rise, these talks will highlight the current basic and clinical research in defining a sex difference, neurobiological causes of such differences, and what benefit animal models can offer in determination of predisposing factors. Talks will highlight potential disease models produced by genetic, prenatal, and hormonal manipulations and will examine the influence of both gonadal and genetic sex in the presentation of disease. Because the reported heightened female sensitivity in these diseases seems to present after puberty, determination of stress pathway maturation is also critical in these studies.

Is being female a predisposing factor toward certain stressrelated diseases? Certainly, females have a heightened stress response, but does this innate physiology dictate elevated disease presentation? To get at the heart of these questions, we must first dissect the underlying neurobiology that is associated with the disease state and reveal how stress becomes a contributing factor in susceptibility. We know the predisposition toward stressrelated diseases such as affective disorders and drug addiction likely involves a genetic vulnerability toward increased stress sensitivity (Nestler et al., 2002; Nestler, 2005). Recent studies examining the involvement of emotionality in addiction point to a likely intersection of stress pathway neurocircuitry with reward centers that may subserve the presentation of these diseases and in their increasingly common comorbidity (de Lecea et al., 2006). As evidence in support of this hypothesis, females show both heightened stress sensitivity and an increased susceptibility toward emotion-based diseases, including depression. Although defining a "sex difference" is complex, it is important in both

Received Aug. 6, 2007; revised Sept. 11, 2007; accepted Sept. 16, 2007.

This work was supported by National Institutes of Health Grants MH070727 (L.M.M.), DA012677 (J.B.B.), DA11717 and DA016556 (J.R.T.), and MH073030 (T.L.B.).

Correspondence should be addressed to Tracy L. Bale, 201E Vet, 6046, University of Pennsylvania, 3800 Spruce Street, Philadelphia, PA 19104. E-mail: tbale@vet.upenn.edu.

DOI:10.1523/JNEUROSCI.3565-07.2007

Copyright $\odot 2007$ Society for Neuroscience $\quad$ 0270-6474/07/2711851-05\$15.00/0 basic and clinical research to distinguish between those features that can be attributed to hormonal modulation (i.e., estrogenic vs androgenic) from that which is a true biological sex difference initiated by genes encoded on the sex chromosomes (Becker et al., 2005; McCarthy and Konkle, 2005).

Orchestration of the components of stress responsivity and recovery can influence a host of endocrine and neuroendocrine factors that may have long-term influences on future sensitivity and ultimately lead to disease if maladaptive in nature. Therefore, the continued ability throughout life to appropriately respond to stress perturbations is a necessary aspect in homeostatic maintenance and disease prevention. If sex differences exist in stressinduced disease susceptibility, then at what level might such sex differences be important? At the level of stress perception, stress physiology, or stress recovery? And when might such distinctions between males and females begin to develop? Before puberty, minimal differences between sexes are detected in the hypothalamic-pituitary-adrenal (HPA) axis stress response (Romeo et al., 2004a,b). Similarly, males and females have equivalent presentation of affective disorders, for both major depression and anxiety, before puberty. During adolescence, maturation of the stress neurocircuitry reveals a blunting of male responsiveness that is likely related to the rise in testosterone (Gomez et al., 2004). After this pubertal period, there is an escalation in female disease presentation compared with males (Angold et al., 1998). Although these clinical findings support an involvement of gonadal hormones in shaping brain plasticity in key emotional centers that are likely to mediate stress responsivity, defining a true sex difference related to disease susceptibility remains unanswered. Do these studies provide evidence for a male-biased "protection" from stress insults leading to disease onset, or is the postpubertal disease rise in females related to a consequence/ interaction of estrogen cyclicity?

\section{Sex and stress neurobiology}

In both humans and rodents, several brain regions involved in stress and corticotropin-releasing factor (CRF)-mediated HPA axis regulation and emotional affect, such as the prefrontal cortex, amygdala, and hippocampus, continue to mature well into adolescence (Fig. 1) (Crews et al., 2007; Sowell et al., 2007). These areas also demonstrate significant sex differences in both structure and function into adulthood (Cahill, 2006). Recent studies 
have begun to clarify whether the onset of these possible sex differences are related to varying rates of maturation between males and females. Neuroimaging studies in humans show that amygdala volume increases significantly more in adolescent boys, whereas hippocampal volume increases faster in girls (Giedd et al., 1997). Moreover, the thinning of frontal cortical gray matter associated with adolescence occurs earlier in females (Giedd et al., 1999), which may be associated with their earlier onset of puberty. Interestingly, these same limbic and forebrain regions are extremely sensitive to hormones released during stress, especially glucocorticoids (McEwen, 2005). Because glucocorticoids are potent modulators of synaptic function and plasticity (Sapolsky, 2003), it is likely that exposure to stressors during adolescence or impaired CRF pathway function would alter the shaping of these areas critical to emotionality, possibly in a sex-dependent manner (Goel and Bale, 2007). Unfortunately, little is known regarding the effects of stress during puberty on the developmental trajectory of these areas in males and females (Romeo and McEwen, 2006). It will be imperative to better identify and delineate the interaction between adolescent development, sex, and stress to determine whether there is a female-biased sex difference in susceptibility to stress-related psychopathologies.

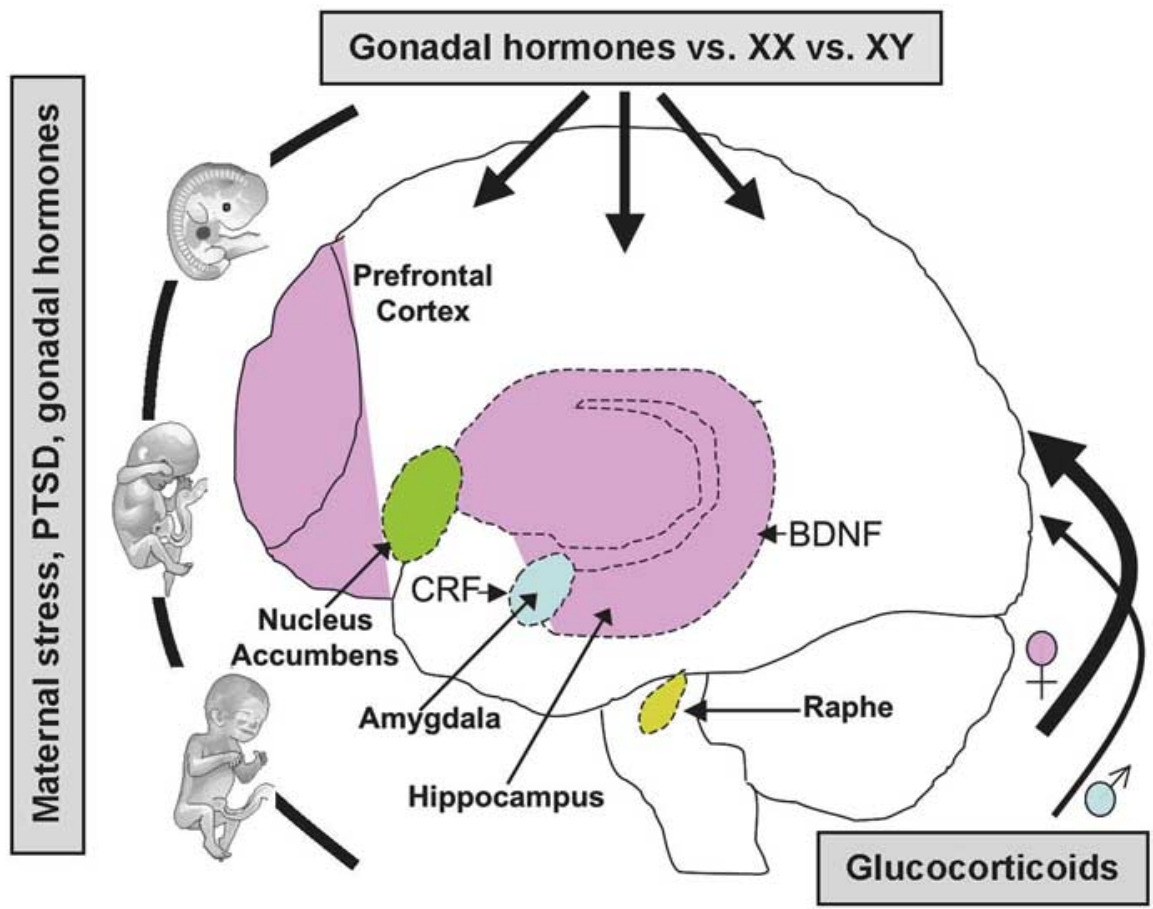

Figure 1. Schematic representing potential brain regions and genes involved in stress-related disease that are implicated in putative sex differences. These brain areas are highly interconnected with one another with numerous efferent and afferent projections involved in emotion, stress reactivity, and reward. Importantly, studies implicate sex differences in structure and/or function as modeled by prenatal or postnatal or adult stress experience. Uterine environment, including stress and gonadal hormones, can influence life susceptibility toward disease. Gonadal hormones (e.g., testosterone, estradiol, and progesterone) and neurotrophic factors (BDNF) elicit effects throughout the lifespan, particularly during perinatal and adolescent development. Sex-specific HPA axis stress responsivity can also promote differing vulnerabilities resulting from higher glucocorticoid levels in females and may be related to central CRF regulation. Hormone-independent, genetically programmed sex differences (XX, XY), and disparate life experiences can also play a role in gender-biased vulnerabilities. Together, these factors may predispose females to a higher incidence of stress-related disorders such as affective disorders and drug abuse.

\section{Stress and addiction behaviors}

In addition to possible inherent sex differences that may occur during normal development, considerable evidence suggests that additional exogenous factors such as stress, maternal care, and the intrauterine environment may have long-lasting health consequences that are sex specific. In humans, prenatal stress is associated with increased anxiety in adolescence (Phillips et al., 2005) and a greater incidence of disease in adulthood (Kessler, 1997; Quenstedt and Parshall, 1998). Studies support a possible link between these prenatal events and development of specific limbic brain regions that are sexually dimorphic. In one rodent model, stress experienced late in gestation produced male offspring with an attenuated HPA response but females with increased anxietyrelated behaviors and a prolonged HPA response (Richardson et al., 2006). These long-term alterations have a temporal specificity dependent on when the stress experience occurs during gestation (Mueller and Bale, 2007). Such sex differences may be one predisposing factor related to addiction behaviors in which early life stress can affect the propensity for drug-taking behavior (Kosten et al., 2004), perhaps by altering the same neural systems that impact novelty seeking (Deminiere et al., 1992).

Addiction is one such disease that appears to have sex-specific traits and vulnerabilities that may be linked to stress. Sex differences in humans are noted in the rate of escalation of drug use in which women tend to increase their drug intake more rapidly than men (Brady and Randall, 1999; Lynch et al., 2002; Hernandez-Avila et al., 2004; Mann et al., 2005). In animal models, sex differences have also been reported during all phases of the addiction process (Lynch et al., 2002; Carroll et al., 2004). For example, when a low dose of drug is used, females acquire cocaine self-administration at a faster rate than males (Lynch, 2006) and display an increased loss of control over their intake (Lynch and Taylor, 2004). Estradiol enhances acquisition of cocaine selfadministration in females (Lynch et al., 2001), as well as the motivation to take cocaine (Hu et al., 2004; Lynch and Roberts, 2004; Lynch and Taylor, 2005; Lynch, 2006). Such results may support more of a role for sex-specific gonadal hormones rather than a true sex difference in such addiction-related output measures. Although stress enhances reinstatement for cocaine responding in males (Shaham et al., 2000; Lu et al., 2003), the interactions between stress and gonadal hormones has not yet been formally established.

Interestingly, little is known with regard to sex-specific neurobiological mechanisms of stress reactivity underlying drug relapse. Although hormonal fluctuations in the rodent estrous cycle undoubtedly show an influence on these behavioral responses to stimulants and stressors, it is also possible that, if sex differences exist, they may be accounted for by the complement of sex chromosomes (XX vs XY) alone or in combination with gonadal hormones. Recent studies have found that locomotor sensitization to cocaine, goal-directed responding, and the development of habitual responding are differentially influenced by sex chromosomes and gonadal hormones (Quinn et al., 2007). Together, studies in this field suggest that an intersection of genetic and gonadal hormone influences provide complex contributions to 
sex differences in vulnerabilities to stress-related diseases, including affective disorders and drug addiction.

\section{Stress and affective disorders}

In addition to a potential for stress to elevate the risk for drug addiction or relapse in a sex-dependent manner, stress also appears to play a profound role in the onset of affective disorders. Although the stress response is essential for maintenance of homeostasis, maladaptive responses to stress can lead to disease, including an elevation in risk factors for depression and anxiety, as well as behaviors associated with drug-taking escalation and relapse (Nemeroff et al., 1984; Nemeroff, 1988; Koob, 1999; Bale, $2005,2006)$. Major depression is one of the most common mental illnesses in both men and women. However, women experience depression at approximately twice the rate of men, and female stress sensitivity has been proposed as a key underlying factor. A critical aspect necessary in defining pathways and mechanisms involved in potential sex differences in such diseases is the development of appropriate animal models to examine alterations in relevant physiology, behavior, gene expression, and cytoarchitectural output measures (Nestler et al., 2002). In such models, exaggerated responses or a failure to respond to stress insults could then be designated as possible biomarkers of affective disorders. For example, in a model of stress sensitivity, we would predict one possible maladaptive response as a failure to alter important gene expression levels, such as the rate-limiting 5 -HT producing enzyme tryptophan hydroxylase-2, that would likely result in an inability to produce appropriate coping strategies. One example of a stress-sensitive model is the CRF receptor-2 deficient mouse that displays exaggerated physiologi$\mathrm{cal}$ and behavioral responses to stress and has been used to explore stress pathway maturation and the prenatal, pubertal, and adult maladaptive stress responses likened to a "depressive" phenotype (Bale et al., 2000, 2003; Coste et al., 2000; Mueller and Bale, 2006; Goel and Bale, 2007). By taking this model one step further, an increased female vulnerability to affective disorders could be explored. Such a manipulation may entail early life feminization or masculinization via prenatal stress or gonadal hormone treatment. For example, males stressed early in gestation show behaviors as adults that are similar to control nonstressed females, suggesting an intersection between sex-specific hormones and brain development (Mueller and Bale, 2007). Evaluation of these models in the context of physiological and behavioral stress responses, both acute and chronic, may define periods of sex-specific plasticity in which stress can be detrimental or predictive of long-term disease risk.

To better develop animal models in which affective disorders can be examined, we need to identify novel gene targets. Recently, such studies have focused on the possible involvement of brainderived neurotrophic factor (BDNF). Loss of BDNF in forebrain regions contributes to a vulnerability for affective disorders, whereas upregulation of BDNF is suggested to mediate the therapeutic effect of antidepressants (Altar, 1999; Duman and Monteggia, 2006; Levinson, 2006). Decreased serum levels of BDNF have been found in depressed patients; however, whether this effect is correlated with gender remains controversial (Karege et al., 2002; Lang et al., 2004). Studies examining effects of stress have found lower levels of BDNF protein in the dentate gyrus of females relative to males (Franklin and Perrot-Sinal, 2006). These results are intriguing because the dentate gyrus is critical for BDNF involvement in behavior and antidepressant efficacy. Male conditional forebrain BDNF knock-outs display normal behaviors, whereas females show increased depression-like behaviors.

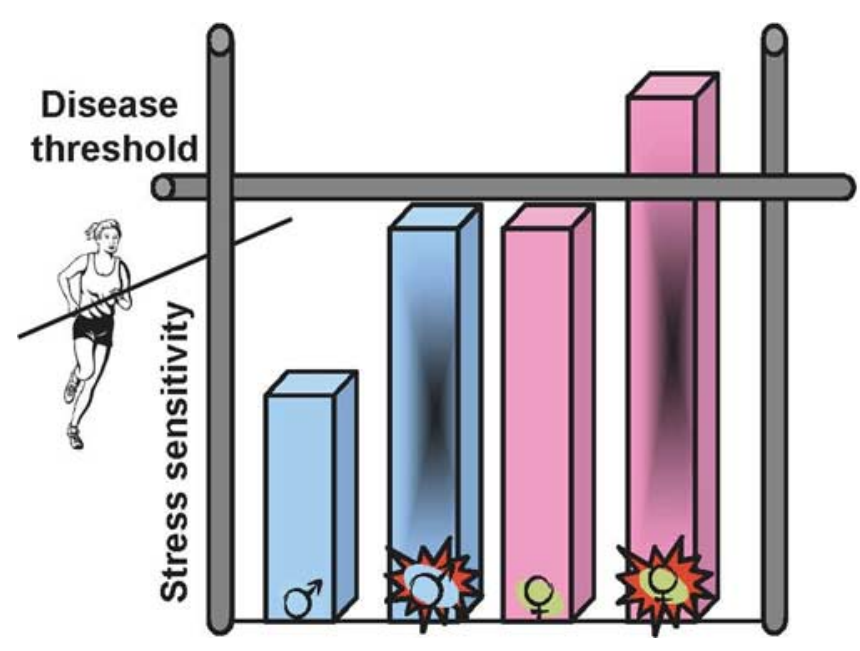

Figure 2. Diagram depicting putative heightened female predisposition toward stressrelated disease. The current state of this provocative field suggests that females basally show an exaggerated sensitivity to stress and that if additional dysregulation occurs (such as may result from prenatal stress, maternal PTSD, or a combined impact of stress and gonadal hormones on brain development), this would push females over a "disease threshold" making them more susceptible. If females do in fact show an increased presentation of certain diseases, such as depression and aspects of drug addiction, then examination of those central pathways regulating stress effects and their downstream targets, including critical feedback mechanisms, may provide greater insight into disease susceptibility, treatment, and prevention.

Interestingly, the loss of BDNF in both sexes attenuated the behavioral actions of an antidepressant, suggesting that the sex differences may be more specific to behavioral responses and coping strategies than to antidepressant efficacy (Monteggia et al., 2007). Elucidating the role of BDNF in depression and its potential contribution to disease vulnerability in females is essential in our search for better drug targets and disease prevention.

\section{Sex differences in clinical studies}

Affective disorders such as posttraumatic stress disorder (PTSD) have also been suggested to have sex-specific traits. However, the question regarding such potential gender differences with respect to life experiences and PTSD outcome is particularly difficult to unpack because men and women differ in the type of experiences they have and may have subjective responses to the same event. For example, men are more often exposed to physical assault but are less likely to develop PTSD to these experiences (Breslau et al., 1999). Conversely, when men are exposed to a personal trauma such as rape, PTSD prevalence rates exceed those reported for women (Kessler et al., 1995). Recent studies have identified shared genetic risk factors for PTSD and exposure to assaultative violence in both combat and noncombat populations (Koenen et al., 2002; Stein et al., 2002). These studies suggest that genetic vulnerability may be important in exposure-related factors. A "genetic predisposition" to PTSD has been more difficult to verify (Roy-Byrne et al., 2006). However, gender appears to play an important role in conferring PTSD risk through possible epigenetic mechanisms (Yehuda et al., 2002, 2005, 2007). Recent studies highlight the importance of maternal, rather than paternal, PTSD as a risk factor for PTSD in offspring. Interestingly, these maternal risk factors for PTSD do not appear to preferentially affect male or female offspring, thus dissociating sex differences in disease risk.

\section{Summary}

Because the reported heightened female predisposition in these diseases seems to present after puberty, determination of stress 
pathway maturation may shed light on whether differences in disease presentation, treatment, and risk are a function of gonadal hormone profiles and/or more inherent to genetic sex (Fig. 2 ). Unarguably, our work in understanding sex differences in these diseases has just scratched the surface. We have only begun exploring the possible involvement of exciting areas such as intrauterine environment, epigenetics, and proteomics in longterm disease risk. An even greater scarcity exists for information on how these regulatory mechanisms could be built into sexspecific outcomes. It is clear, to answer the question of whether "being female is a predisposing factor," we are in desperate need of novel animal models and paradigms (Kalueff et al., 2007), in which such comparisons can be carefully studied.

\section{References}

Altar CA (1999) Neurotrophins and depression. Trends Pharmacol Sci 20:59-61.

Angold A, Costello EJ, Worthman CM (1998) Puberty and depression: the roles of age, pubertal status and pubertal timing. Psychol Med 28:51-61.

Bale TL (2005) Sensitivity to stress: dysregulation of CRF pathways and disease development. Horm Behav 48:1-10.

Bale TL (2006) Stress sensitivity and the development of affective disorders. Horm Behav 50:529-533.

Bale TL, Contarino A, Smith GW, Chan R, Gold LH, Sawchenko PE, Koob GF, Vale WW, Lee KF (2000) Mice deficient for corticotropin-releasing hormone receptor-2 display anxiety-like behaviour and are hypersensitive to stress. Nat Genet 24:410-414.

Bale TL, Anderson KR, Roberts AJ, Lee KF, Nagy TR, Vale WW (2003) Corticotropin-releasing factor receptor-2-deficient mice display abnormal homeostatic responses to challenges of increased dietary fat and cold. Endocrinology 144:2580-2587.

Becker JB, Arnold AP, Berkley KJ, Blaustein JD, Eckel LA, Hampson E, Herman JP, Marts S, Sadee W, Steiner M, Taylor J, Young E (2005) Strategies and methods for research on sex differences in brain and behavior. Endocrinology 146:1650-1673.

Brady KT, Randall CL (1999) Gender differences in substance use disorders. Psychiatr Clin North Am 22:241-252.

Breslau N, Chilcoat HD, Kessler RC, Peterson EL, Lucia VC (1999) Vulnerability to assaultive violence: further specification of the sex difference in post-traumatic stress disorder. Psychol Med 29:813-821.

Cahill L (2006) Why sex matters for neuroscience. Nat Rev Neurosci 7:477-484

Carroll ME, Lynch WJ, Roth ME, Morgan AD, Cosgrove KP (2004) Sex and estrogen influence drug abuse. Trends Pharmacol Sci 25:273-279.

Coste SC, Kesterson RA, Heldwein KA, Stevens SL, Heard AD, Hollis JH, Murray SE, Hill JK, Pantely GA, Hohimer AR, Hatton DC, Phillips TJ, Finn DA, Low MJ, Rittenberg MB, Stenzel P, Stenzel-Poore MP (2000) Abnormal adaptations to stress and impaired cardiovascular function in mice lacking corticotropin-releasing hormone receptor-2. Nat Genet 24:403-409.

Crews F, He J, Hodge C (2007) Adolescent cortical development: a critical period of vulnerability for addiction. Pharmacol Biochem Behav 86:189-199.

de Lecea L, Jones BE, Boutrel B, Borgland SL, Nishino S, Bubser M, DiLeone $\mathrm{R}$ (2006) Addiction and arousal: alternative roles of hypothalamic peptides. J Neurosci 26:10372-10375.

Deminiere JM, Piazza PV, Guegan G, Abrous N, Maccari S, Le Moal M, Simon H (1992) Increased locomotor response to novelty and propensity to intravenous amphetamine self-administration in adult offspring of stressed mothers. Brain Res 586:135-139.

Duman RS, Monteggia LM (2006) A neurotrophic model for stress-related mood disorders. Biol Psychiatry 59:1116-1127.

Franklin TB, Perrot-Sinal TS (2006) Sex and ovarian steroids modulate brain-derived neurotrophic factor (BDNF) protein levels in rat hippocampus under stressful and non-stressful conditions. Psychoneuroendocrinology 31:38-48.

Giedd JN, Castellanos FX, Rajapakse JC, Vaituzis AC, Rapoport JL (1997) Sexual dimorphism of the developing human brain. Prog Neuropsychopharmacol Biol Psychiatry 21:1185-1201.

Giedd JN, Blumenthal J, Jeffries NO, Castellanos FX, Liu H, Zijdenbos A, Paus
T, Evans AC, Rapoport JL (1999) Brain development during childhood and adolescence: a longitudinal MRI study. Nat Neurosci 2:861-863.

Goel N, Bale TL (2007) Identifying early behavioral and molecular markers of future stress sensitivity. Endocrinology 148:4585-4591.

Gomez F, Manalo S, Dallman MF (2004) Androgen-sensitive changes in regulation of restraint-induced adrenocorticotropin secretion between early and late puberty in male rats. Endocrinology 145:59-70.

Hernandez-Avila CA, Rounsaville BJ, Kranzler HR (2004) Opioid-, cannabis- and alcohol-dependent women show more rapid progression to substance abuse treatment. Drug Alcohol Depend 74:265-272.

Hu M, Crombag HS, Robinson TE, Becker JB (2004) Biological basis of sex differences in the propensity to self-administer cocaine. Neuropsychopharmacology 29:81-85.

Kalueff AV, Wheaton M, Murphy DL (2007) What's wrong with my mouse model? Advances and strategies in animal modeling of anxiety and depression. Behav Brain Res 179:1-18.

Karege F, Perret G, Bondolfi G, Schwald M, Bertschy G, Aubry JM (2002) Decreased serum brain-derived neurotrophic factor levels in major depressed patients. Psychiatry Res 109:143-148.

Kessler RC (1997) The effects of stressful life events on depression. Annu Rev Psychol 48:191-214.

Kessler RC, Sonnega A, Bromet E, Hughes M, Nelson CB (1995) Posttraumatic stress disorder in the National Comorbidity Survey. Arch Gen Psychiatry 52:1048-1060.

Koenen KC, Harley R, Lyons MJ, Wolfe J, Simpson JC, Goldberg J, Eisen SA, Tsuang M (2002) A twin registry study of familial and individual risk factors for trauma exposure and posttraumatic stress disorder. J Nerv Ment Dis 190:209-218.

Koob GF (1999) Stress, corticotropin-releasing factor, and drug addiction. Ann NY Acad Sci 897:27-45.

Kosten TA, Sanchez H, Zhang XY, Kehoe P (2004) Neonatal isolation enhances acquisition of cocaine self-administration and food responding in female rats. Behav Brain Res 151:137-149.

Lang UE, Hellweg R, Gallinat J (2004) BDNF serum concentrations in healthy volunteers are associated with depression-related personality traits. Neuropsychopharmacology 29:795-798.

Levinson DF (2006) The genetics of depression: a review. Biol Psychiatry 60:84-92.

Lu L, Shepard JD, Hall FS, Shaham Y (2003) Effect of environmental stressors on opiate and psychostimulant reinforcement, reinstatement and discrimination in rats: a review. Neurosci Biobehav Rev 27:457-491.

Lynch WJ (2006) Sex differences in vulnerability to drug selfadministration. Exp Clin Psychopharmacol 14:34-41.

Lynch WJ, Roberts DC (2004) Effects of cocaine self-administration on food-reinforced responding using a discrete trial procedure in rats. Neuropsychopharmacology 29:669-675.

Lynch WJ, Taylor JR (2004) Sex differences in the behavioral effects of 24$\mathrm{h} /$ day access to cocaine under a discrete trial procedure. Neuropsychopharmacology 29:943-951.

Lynch WJ, Taylor JR (2005) Decreased motivation following cocaine selfadministration under extended access conditions: effects of sex and ovarian hormones. Neuropsychopharmacology 30:927-935.

Lynch WJ, Roth ME, Mickelberg JL, Carroll ME (2001) Role of estrogen in the acquisition of intravenously self-administered cocaine in female rats. Pharmacol Biochem Behav 68:641-646.

Lynch WJ, Roth ME, Carroll ME (2002) Biological basis of sex differences in drug abuse: preclinical and clinical studies. Psychopharmacology (Berl) 164:121-137.

Mann K, Ackermann K, Croissant B, Mundle G, Nakovics H, Diehl A (2005) Neuroimaging of gender differences in alcohol dependence: are women more vulnerable? Alcohol Clin Exp Res 29:896-901.

McCarthy MM, Konkle AT (2005) When is a sex difference not a sex difference? Front Neuroendocrinol 26:85-102.

McEwen BS (2005) Glucocorticoids, depression, and mood disorders: structural remodeling in the brain. Metabolism 54:20-23.

Monteggia LM, Luikart B, Barrot M, Theobold D, Malkovska I, Nef S, Parada LF, Nestler EJ (2007) Brain-derived neurotrophic factor conditional knockouts show gender differences in depression-related behaviors. Biol Psychiatry 61:187-197.

Mueller BR, Bale TL (2006) Impact of prenatal stress on long term body weight is dependent on timing and maternal sensitivity. Physiol Behav 88:605-614. 
Mueller BR, Bale TL (2007) Early prenatal stress impact on coping strategies and learning performance is sex dependent. Physiol Behav 91:55-65.

Nemeroff CB (1988) The role of corticotropin-releasing factor in the pathogenesis of major depression. Pharmacopsychiatry 21:76-82.

Nemeroff CB, Widerlov E, Bissette G, Walleus H, Karlsson I, Eklund K, Kilts CD, Loosen PT, Vale W (1984) Elevated concentrations of CSF corticotropin-releasing factor-like immunoreactivity in depressed patients. Science 226:1342-1344.

Nestler EJ (2005) Is there a common molecular pathway for addiction? Nat Neurosci 8:1445-1449.

Nestler EJ, Barrot M, DiLeone RJ, Eisch AJ, Gold SJ, Monteggia LM (2002) Neurobiology of depression. Neuron 34:13-25.

Phillips NK, Hammen CL, Brennan PA, Najman JM, Bor W (2005) Early adversity and the prospective prediction of depressive and anxiety disorders in adolescents. J Abnorm Child Psychol 33:13-24.

Quenstedt M, Parshall A (1998) Prenatal exposure to maternal stress and subsequent schizophrenia. Br J Psychiatry 173:183.

Quinn JJ, Hitchcott PK, Umeda EA, Arnold AP, Taylor JR (2007) Sex chromosome complement regulates habit formation. Nat Neurosci, in press.

Richardson HN, Zorrilla EP, Mandyam CD, Rivier CL (2006) Exposure to repetitive versus varied stress during prenatal development generates two distinct anxiogenic and neuroendocrine profiles in adulthood. Endocrinology 147:2506-2517.

Romeo RD, McEwen BS (2006) Stress and the adolescent brain. Ann NY Acad Sci 1094:202-214.

Romeo RD, Lee SJ, McEwen BS (2004a) Differential stress reactivity in intact and ovariectomized prepubertal and adult female rats. Neuroendocrinology 80:387-393.
Romeo RD, Lee SJ, Chhua N, McPherson CR, McEwen BS (2004b) Testosterone cannot activate an adult-like stress response in prepubertal male rats. Neuroendocrinology 79:125-132.

Roy-Byrne PP, Noonan C, Afari N, Buchwald D, Goldberg J (2006) Is the association between posttraumatic stress disorder symptoms and poor health due to a common familial or genetic factor? Gen Hosp Psychiatry 28:408-413.

Sapolsky RM (2003) Stress and plasticity in the limbic system. Neurochem Res 28:1735-1742.

Shaham Y, Erb S, Stewart J (2000) Stress-induced relapse to heroin and cocaine seeking in rats: a review. Brain Res Brain Res Rev 33:13-33.

Sowell ER, Peterson BS, Kan E, Woods RP, Yoshii J, Bansal R, Xu D, Zhu H, Thompson PM, Toga AW (2007) Sex differences in cortical thickness mapped in 176 healthy individuals between 7 and 87 years of age. Cereb Cortex 17:1550-1560.

Stein MB, Jang KL, Taylor S, Vernon PA, Livesley WJ (2002) Genetic and environmental influences on trauma exposure and posttraumatic stress disorder symptoms: a twin study. Am J Psychiatry 159:1675-1681.

Yehuda R, Halligan SL, Bierer LM (2002) Cortisol levels in adult offspring of Holocaust survivors: relation to PTSD symptom severity in the parent and child. Psychoneuroendocrinology 27:171-180.

Yehuda R, Engel SM, Brand SR, Seckl J, Marcus SM, Berkowitz GS (2005) Transgenerational effects of posttraumatic stress disorder in babies of mothers exposed to the World Trade Center attacks during pregnancy. J Clin Endocrinol Metab 90:4115-4118.

Yehuda R, Blair W, Labinsky E, Bierer LM (2007) Effects of parental PTSD on the cortisol response to dexamethasone administration in their adult offspring. Am J Psychiatry 164:163-166. 